\title{
Models of Personal Semantic Regulation in the Digital Age
}

\author{
Tatiana Leshkevich ${ }^{1, *}$ Anna Motozhanets ${ }^{1, a}$
}

\author{
${ }^{1}$ Southern Federal University, Rostov-on-Don, Russia \\ aEmail: annamt@bk.ru \\ *Corresponding author. Email: Leshkevicht@mail.ru
}

\begin{abstract}
The article considers transformations in semantic regulations in the digital age and provides a philosophical analysis of self-regulation patters from three different perspectives. Firstly, the authors analyze the mundane pattern of self-regulation, secondly, characteristics of the existential pattern of semantic regulation are revealed, and finally, the article describes specificity of reflexive self-regulation in the context of contemporary social transformations. The research is based on such innovative methodological tools as the concepts of attractiveness, fractality, emergence and enactivism, the system of values and ambitions. Special emphasis is placed on the concept of complexity, which defines the spirit of the 21st century. The authors also use the methods of theoretic structuring and subjectoriented approach, which links semantic regulations with the subject. The research relies on theories by such Russian scholars as M. Bakhtin, V. Nalimova, S.L. Rubinstein, O. Chistyakova as well as fundamental ideas by S. Kierkegaard, P. Ricoeur, E. Husserl and others. The insight into the patterns of semantic regulation helps reveal its peculiarities and programming effect. Behavior patterns within a mundane model, which often lacks reflection, are usually practice-oriented and are based on the mechanisms of role-aware conformity. They are "self-explanatory" in a mundane way and define a new way of adapting to the digital world by means of self-development based on media-content consumption. The Internet creates an illusion of surmounting the limitations of the meaningfulness of day-to-day practices. Existential model of semantic regulation is an open-ended project of one's life choices and one's self-fulfillment. In the context of the digital world existential model correlates with the value system of the information world and is vulnerable to manipulative influence. Reflexive model aims at comprehending genuine meaning of events and a person's self-embodied existence; within a reflexive model, digital opportunities are viewed as one of the mediators between a person and the modern world. The energy of semantic regulations should be channeled towards "strategic reasoning" and humanitarian values.
\end{abstract}

\section{Keywords: semantic regulations, digital age, mundane pattern, reflexive model}

\section{INTRODUCTION}

The modern epoch is viewed as a "broad unity", which includes a variety of semantic regulation models. Semantic regulations are attached to a person, who is a carrier of meaning, and are subject to transformations under the influence of digital determination.

Behavior patterns are increasingly influenced by the digital environment, ranking generations in terms of digital skills. Surfing the net has become a general denominator of the digital age. For an average user the instruction of what button to click becomes a priority. Life gets filled with a different, virtual factuality, the 00298A. simulative nature of which is taken for granted. In this context, the interconnection between the image of the world and one's self-determination in a digital environment is of particular relevance.

The study of transformations in semantic regulations is based on innovative methodological tools. The concept of attractiveness defines the mechanisms of the dominating value system. The concept of emergence helps to take account of spontaneous situational scenarios and unexpected circumstances that change the chosen behavior strategies. According to some scholars, the concept of enactivism helps to understand to what extent our perception is defined by our inner self, by what we do, what happens to us [1]. Enactivism defines 
transformations in semantic regulations due to the changes of external circumstances produced by the subject. The concept of fractality defines the feature of self-similarity illustrating the fact that one element of being can represent the whole. Fractality enables us to reveal the direction of semantic regulation by one single act. Contemporary geopolitical situation is defined by instability, uncertainty and riskiness. The concept of complexity reveals challenges of our existence and needs comprehension. When studying semantic regulations, the following methods may be effective: the method of theoretic structuring and subject-oriented approach, which correlates life-meaning reflection with the subject, his rationality and initiative. The abovementioned methodological tools enable us to provide a comprehensive analysis of semantic regulations of modern existence in the context of the digital environment.

\section{MUNDANE PATTERN OF SEMANTIC REGULATION IN THE DIGITAL AGE}

The analysis of daily life practices reveals a number of peculiarities. Firstly, a mundane pattern of semantic regulation generates consistency in the process of goalsetting. As a rule, the expected empiric regularities revolve around primary and urgent daily needs with minor variations. These sequences reproduce a set of material determiners, traditions and life experience patterns which lack reflection. This is a repeating pattern which is characterized by the interconnection between natural environment and human life. As the Russian philosopher V. Rosanov notes, 'gathering berries in summer - eating berry jam in winter'. Sensual forms of expression have a habitual character, being reproduced in similar circumstances, they are based on immediate practice-oriented programmes.

Secondly, everyday practices focus on the concreteness of sensual experience. Time is divided into separate periods embracing separate episodes of everyday practices. Generalizations do not go beyond summing up examples of empirical experience. Semantic regulations are aimed at solving urgent problems. There is a concrete causation based on the mechanisms of role behavior. A person is seen as holding a certain status, playing a certain role. Everyday life practices is a space for individual selfformation. Within a mundane model of semantic regulation an actor is viewed as a representative of a particular social group.

In the third place, a man of the mundane leads his own private life. Family underlies patrimonial selfconsciousness, which is targeted at descendants. Social and political events become relevant only if they influence private life. While private life is always kept private without being subject to public disclosure. $\mathrm{M}$. Bakhtin describes private life as a "dark grave, where there is no sunshine and no starry sky" [2]. Within the dimension of the mundane, semantic regulations largely depend on the "biographical conflict resolution ", and sometimes on the desire to survive.

A person's activity is aimed at transforming rationality to practicability. Pragmatic approach to life, that makes a person benefit-oriented, often deprives him of self-fulfillment and prevents him from reaching life goals, turning life into a battle for survival.

The model described above is rooted in the notion of stability and denies random experience. Due to the fact that semantic regulations are identified with stereotypes and traditions, taboos and conventions, they are characterized by the idea that actions and events are universally interpreted in a similar way. Everyday life practices are self-explanatory. Meanings become superficially adapted to contemporary world with a slight shift to local and reginal ethnic dimensions. As a rule, the mundane model of semantic regulation contains intrinsic intentions, which revolve around the notion of «home» and are aimed at consensus, empathy and compatibility. Although mundane discourse often consists of versatile fragments, economic trend adds a discursive-mundane rationality.

At the same time the mundane model of semantic regulation, which is based on the concept "home", possesses great vitality and illustrates a person's dependence on daily needs and worries. Even if a person tries to overcome the limitations of the mundane, he can't be completely independent of it. A combination of everyday life conventions forms a lower layer of a person's life-meaning orientations. Having limited horizons and distinctive features, everyday life practices impose themselves upon a person. However, digital environment modifies semantic regulations because Internet technologies create an illusion of overcoming limitations of the mundane pattern. Mediacontent consumption becomes the basic value of everyday life. Thus, massive digitalization generates a new type of adaptation to the digital world, imposing its pattern of activity distribution. In our hectic life our urge to find the true meaning of life is largely weakened. In other words, a person does not bother to reflect on the meaning of life, but if he does, it means that he is ready to adopt a new model of existence.

\section{EXISTENTIAL MODEL OF SEMANTIC REGULATION}

Unlike the mundane pattern, existential model emphasizes the importance of a person's integral bodily-spiritual experience and the cultural dimension of his existence. Here we mean a certain shift of conventional routine margins of mundane existence towards an integral bodily-spiritual worldview. What is essential here is the demarcation line between a full life 
on the one hand and the mode of existence on the other, which can mean wretched existence. An independent life choice is connected with a person's intimate inner world, a variety of feelings and emotional experiences. The image of reality is constructed through individual perceptions.

Existential model of semantic regulation is revealed through a person's narrative activity, i.e. what a person can tell others of himself [3]. The "narrative" interpretation of significant events leads to selfunderstanding, revealing essential orientations.

This model relies on various interpretations of the "I exist ..." statement. According to E. Husserl, we exist "...in the form of the struggle for the truth for us, the struggle to make ourselves be true" [4]. Rene Descarte's «cogito ergo sum» - "I think, therefore I am"- has a lasting value. Together with Berkeley's "to be is to be perceived". Finally, A. Camus" "I rebel, therefore I exist" is a manifesto of radical action. All the above-mentioned variety of self-expression is embraced by V. Nalimov's idea that the meaning is the organizing principle of human life [5]. When searching for semantic orientations, existential analysis is based on both rational and spiritual, intuitive dimension of human existence. Hence, we cannot but mention theocentrism, which plays an essential part in searching for the meaning of life. In theocentrism, the center of universe and human life is God. Scholars note that a person's life goal, his relationship with God, dichotomy of body and soul have been disputed since the Church Fathers. It was concluded that the idea of salvation determines a person's righteous path and directs a person to self-improvement and spiritual unity with God [6]. In this regard, we cannot fail to mention the three-stage rise to genuine existence, proposed by S. Kierkegaard, whereas the final third stage involves religious self-concentration. This stage is preceded by aesthetic and ethical stages. At the first aesthetic stage, which is connected with being, pursuing excellence is the main orientation. The second ethical stage accentuates a sense of duty, moral law and moral responsibility [7].

In the context of modernity with its complexity, uncertainty and riskiness we may adopt the following stance on the existential model. Firstly, existential model of semantic regulation is an open-ended model, which is aimed at a person's self-fulfillment. In the digital civilization it is shifted to the Information world and correlates with its value system. Secondly, existential model accumulates the dynamics of life choices focusing on attractors. Scholars view positive scenarios and emotions such as joy, happiness, the sense of accomplishment to be the most powerful attractors. However, negative emotions like boredom, weariness, bitterness of defeat, may also play their part [8]. Thirdly, existential model of semantic regulation implies multiplicity of mental spaces that channel the meanings. A person's behavior is largely governed by sympathies and antipathies, love and aversion. Thus, this model involves a variety of behavior patterns including existentially disorienting ones, which devaluate the meanings of human existence. The modern era lacks humanitarian basis, which leads to an increasing number of depressive disorders, loss of motivation, various forms of addiction and escapism as an attempt to hide from information overload and stressful reality. All the above-mentioned illustrates the process of estrangement from reality, the destruction of its value system.

Philosophical analysis of the existential model of semantic regulation reveals a certain barrier set by the digital era, that consists in a straightforward correlation between the urge for self-fulfillment and mastering digital skills. This way of interacting with the Information world has already generated a new type of subject - the so-called "content viewer" who relies on superficial information scanning [9]. Then follows a "multitasker" who is constantly overloaded with information and is always ready to switch from one activity to another. A multitasker tries to combine professional activity with consuming entertaining online content, to combine various types of online interaction with involvement in information events. This testifies to the fact that there is an inextricable connection between life and digital environment and the search for life-meaning regulations lacks reflection. Digital determination cannot explain a variety of meanings, motivations and manifestations of human existence. Hence, we cannot view digital interactions as a reference pattern of all forms of human interaction.

\section{REFLEXIVE MODEL AND ITS MEANINGFUL IMPERATIVES}

We can a priori state the gap between the mundane and existential models on the one hand and the reflexive model on the other. The latter involves independent reasoning, the ability to identify negative consequences of various events. Reflexive model underlies the search of coherence between a person's self-cognition (one's inner self) and comprehending the external life as the space of one's own existence. In other words, reflexive model is aimed at revealing genuine meaning of events in in relation to the meanings of a reasonable and full-fledged human existence.

According to S.L. Rubinstein, consciousness is a cornerstone of being. The author emphasizes that the subject of consciousness embraces the whole being, comprehends being by means of contemplation, thus presenting a part of the whole [10]. 
The analysis of the reflexive model reveals its fundamental features. Firstly, reflection should be viewed as the "shuttle movement" of mind, switching from presuppositions to projecting their meaning on the present state. Reflexivity is characterized by intensive self-consciousness and skepticism, which makes it resistant to frustration.

Secondly, reflexive model of semantic regulations effects consequences and situational meaning of the event line, without trying to decipher the origins. This is where theoretic structuring plays an essential part because it enables one to consider factors that are beyond direct observation. Apart from comprehending the present, consciousness is capable of making a specific "investment" in the future, defining the future perspective and a variety of possibilities.

Thirdly, altering the importance of events and processes, reflection presupposes redirecting actions involved. Reflection demands action and at the same time it accompanies action, keeping record of ongoing change. Thus, activist approach is a part of the reflexive model of semantic regulations. According to this approach, contemplating should be accompanied by acting aimed at going beyond circumstances.

The desire to be a "homo sapiens" gives rise to the intention for self-control. Within the reflexive model a person tries to bring his life circumstances under control. A person becomes a constitutive subject, i.e. a subject that is capable of objectifying its own essence. All the above-mentioned illustrates the fact that the reflexive model is subject-oriented and testifies to the measure of rationality of a modern man. It aims to introduce goals and objectives into various life practices, to add meaning to one's choices. In this context, of great importance is the problem of "decoding" or "unpacking" individual meanings of being [11]. Meaning-making takes place in a multidimensional space including the sphere of entrepreneurial activity, the dimension of spiritual quest, implementing natural abilities and social dimension of self-fulfillment.

It should be mentioned here that the reflexive model relies on retrospective reflection, which enables us to view semantic regulations through the prism of the Eastern wisdom and Classical antiquity. The former provides us with the Confucian formula: "love your family", "love people", "love all creatures". The latter suggests a universal imperative of the classical "Golden Middle" and measure in everything, which should correlate with any person's activity.

The analysis of the reflexive model of semantic regulation reveals the imperatives that it contains. Firstly, the meaning of a person's life is connected with a person's self-fulfillment. Secondly, semantic regulations contribute to structuring one's own Self, independence of mind and strong will, and enable a person to "look" beyond his own life practices and think on a scale of "strategic reasoning". Thirdly, the system of values plays an important role in structuring semantic shifts in the modern society. It should be mentioned here that on a global scale the choice of semantic regulations should be defined by humanitarian goals and aimed at maintaining fair and non-violent world order. Hence, the reflexive model of semantic regulation serves as a reliable basis for a man-centered future.

\section{Conclusion}

Human sociality has shared meanings and mutual understanding as its basic components. However, contemporary life processes are largely characterized by uncertainty, which blurs conventional life-meaning orientations. Having looked into the issue, we come to the following conclusions. In the modern world a person has to live in the framework of several semantic patterns, all of which have a regulatory influence. All semantic models have a common feature: the initial motivation, that is generated within one or another semantic orientation, is largely influenced by digital determination, which makes a person want to transfer his self to a digital space. Digitalization changes the rules of life, bringing about various transformations in the models of semantic regulations, and transfers the whole system of moral values and principles to the dimension of information technologies [12].

The mundane model is characterized by a low degree of personal semantic regulation as the sphere of strategic capabilities lies beyond this pattern. Human activity is gradually transferred to 3D virtual reality characterized by strong sensations, visual and emotional pleasures, manifestation of entertainment as the main value. Internet creates the illusion of overcoming limitations of the mundane existence.

Existential model of semantic regulation reveals the dangers of virtual simulative effects, which drag a person into the sphere of manipulative influence, change his worldview and behavior patterns. In this context the process of "decoding" personal meanings of existence becomes more complex as virtual simulations impose upon a person a certain worldview.

The reflexive model of semantic regulation seems to overcome the limitations of the above-mentioned models. Within this model a person is capable of combining the past and the future perspective in his perceptions and views digitalization and Internet technologies as a means of communication with contemporary world. He strives for self-fulfillment, the depth and freedom of communication. The reflexive pattern goes beyond digital approach and cannot be reduced to digital values. Hence, developing "digital skills" should be accompanied by creativity and critical 
thinking, humanitarian values and strategic reasoning. The potential of semantic regulations should be channeled towards humanitarian values both in the sphere of individual life practices and on a global scale.

\section{References}

[1] A. Noë, Out of Our Heads. Why You Are Not Your Brain, and Other Lessons from the Biology of Consciousness, New York, Hill and Wang, 2009.

[2] M. Bakhtin, "Forms of time and chronotope in a novel. Essays in historic poetics" in Voprosy Literatury i Estetiki, SPb-M., Hudozhestvennaja Literatura, 1975, pp.234-407, (in Russian).

[3] P. Ricoeur, Oneself as Another, Translated from French by Kathleen Blamey, Chicago, London, The University of Chicago Press, 1994.

[4] E. Husserl, "Crisis of European science and transcendental phenology. Lead-in to phenomenological philosophy" in Voprosy Fiolosofii, 1992, № 7, p. 143.

[5] V. Nalimov, Looking for the New Meanings, Moscow, Centr Gumanitarnikh Initsiativ, 2013, p. 464 (in Russian).

[6] O. Chistyakova, "Religious anthropology of Eastern (GreekByzantine) Patristics" in European Journal of Science and Theology, December 2019, Vol. 15, № 6, pp. 145-155.

[7] S. Kierkegaard, Episode from Life: in 2 parts, SPb, Izdatelstvo Russkoj Hristianskoj Gumanitarnoj Akademii, Amfora, 2011, p. 823 (in Russian).

[8] V. Branskiy, S. Pozharskiy, I. Mikailova et al, "The Global Development of Mankind in Terms of Synergetic Historicism", in Voprosy Filosofii, 2017, №5, pp. 55-65 (in Russian).

[9] T. Leshkevich, "Digital transformations of the age and their influence on the modern man" in Vestnik Tomskogo Gosudarstvennogo Universiteta, 2019, № 439, p. 106 (in Russian).

[10] S. Rubinstein, Being and Consciousness. Man and World, St. Petersburg: Peter Publishing House, 2003.

[11] T. Leshkevich, "The problem of the quality unpacking the meanings of being" in Nauchnaja Misl Kavkasa, Rostov-onDon, SFU, 2014, №4, pp.14-22.

[12] J. Sullins, "Information Technology and Moral Values" in The Stanford

[13] Encyclopedia of Philosophy, Winter 2018 Edition, Edward N. Zalta (ed.) 2018 ,

URL https://plato.stanford.edu/archives/win2018/entries/it-moralvalues/ 